\title{
A lithium nucleation-diffusion-growth mechanism to govern the horizontal deposition of lithium metal anode
}

\author{
Jing $\mathrm{Yu}^{1,2 \dagger}$, Kai Shi ${ }^{1,2 \dagger}$, Siwei Zhang ${ }^{3 \dagger}$, Danfeng Zhang ${ }^{1,2}$, Likun Chen ${ }^{1,2}$, Song $\mathrm{Li}^{1,2}$, Jiabin Ma ${ }^{1,2}$, \\ Heyi $\mathrm{Xia}^{1,2}$ and Yan-Bing $\mathrm{He}^{1^{*}}$
}

\begin{abstract}
The severe lithium (Li) dendrite growth leads to poor cycling stability and serious safety hazards of $\mathrm{Li}$ metal batteries, which completely impedes their practical applications. Herein, a novel $\mathrm{Li}$ nucleation-diffusion-growth mechanism based on $\mathrm{Li}$-Sn alloy/Li $\mathrm{L}_{3} \mathrm{~N}$ electrolyte (LS/LN) composite interface layer is proposed, which synergistically guides the horizontal deposition of $\mathrm{Li}$ to suppress the vertical growth of $\mathrm{Li}$ dendrite and side reactions with the electrolyte. The lithiophilic Li-Sn alloy captures $\mathrm{Li}$ ions to nucleate preferentially on the alloy sites, and simultaneously the $\mathrm{Li}_{3} \mathrm{~N}$ with low diffusion energy barrier and high Li-ion conductivity efficiently transports $\mathrm{Li}$ ions to nucleation sites during $\mathrm{Li}$ plating, consequently promoting the Li horizontal deposition. As a result, the LS/LN-Li symmetric cells can stably cycle $1600 \mathrm{~h}$ even at a high current density of $5 \mathrm{~mA} \mathrm{~cm}$ and deposition capacity of $5 \mathrm{~mA} \mathrm{~h} \mathrm{~cm}{ }^{-2}$. The $\mathrm{LiFePO}_{4} \mid \mathrm{LS} / \mathrm{LN}-\mathrm{Li}$ cells with a high loading of $8.2 \mathrm{mg} \mathrm{cm}^{-2}$ present a high capacity retention of $93.4 \%$ after 1000 cycles, much higher than that using bare $\mathrm{Li}$ (64.8\%). Furthermore, the $\mathrm{LiNi}_{0.8} \mathrm{Co}_{0.1} \mathrm{Mn}_{0.1} \mathrm{O}_{2} \mid \mathrm{LS} / \mathrm{LN}-\mathrm{Li}$ cells present more excellent cycling stability than the cells using bare Li. The Li nucleation-diffusion-growth mechanism opens a promising route to solve the challenge of the vertical growth of Li dendrite and achieve highly stable Li metal batteries.
\end{abstract}

Keywords: lithium horizontal growth, $\mathrm{Li}-\mathrm{Sn}$ alloy, $\mathrm{Li}_{3} \mathrm{~N}$, lithium dendrite, lithium metal anode

\section{INTRODUCTION}

The growing demand for high-energy-density lithium-ion batteries from portable devices and electric vehicles has motivated the development of Li metal anode (LMA) due to its high theoretical specific capacity $\left(3860 \mathrm{~mA} \mathrm{~h} \mathrm{~g}^{-1}\right)$, low potential $(-3.040 \mathrm{~V} v s$. standard hydrogen electrode), and low density $\left(0.534 \mathrm{~g} \mathrm{~cm}^{-3}\right)$ [1-5]. Moreover, LMA is essential for the application of various high-specificcapacity cathode materials (such $\mathrm{S}$ and $\mathrm{O}_{2}$ ) [6]. Unfortunately, the low coulombic efficiency (CE), inferior cycling stability, and severe safety hazards of LMA seriously hinder its commercial applications [7-9]. The uncontrolled $\mathrm{Li}$ dendrite growth induced by uneven electric field distribution and nucleation sites is to blame for these problems [10]. Firstly, the dendritic Li would inevitably lead to the continuous consumption of liquid electrolyte and active Li due to the repeated rupture and repair of the fragile solid electrolyte interphase (SEI) caused by the virtually infinite volume change of $\mathrm{Li}$ metal during Li plating/stripping [11-13]. Meanwhile, Li dendrites also easily lose electron contact with LMA host during stripping and then convert to dead $\mathrm{Li}$, resulting in an increase of interfacial resistance and drastically reduced CE [14-16]. More seriously, the continuously vertical growth of Li dendrite would pierce the separator, and finally trigger the short circuit as well as thermal runaway of Li metal batteries [17-19]. Considerable research efforts have been dedicated to solving the above problems. One route is to construct a three-dimensional (3D) host with a high surface area such as 3D metal skeleton [20-22], 3D carbon nanostructures [23-25], and 3D Li-based framework [26,27], which can lower local current density, homogenize the Li-ion distribution and

\footnotetext{
${ }^{1}$ Shenzhen Geim Graphene Center, Tsinghua Shenzhen International Graduate School, Shenzhen 518055, China

${ }^{2}$ Laboratory of Advanced Materials, School of Materials Science and Engineering, Tsinghua University, Beijing 100084, China

${ }^{3}$ Shenzhen Environmental Science and New Energy Technology Engineering Laboratory, Tsinghua-Berkeley Shenzhen Institute (TBSI), Tsinghua University, Shenzhen 518055, China

† Theses authors contributed equally to this work.

* Corresponding author (email: he.yanbing@sz.tsinghua.edu.cn)
} 
alleviate volume expansion during Li plating/stripping $[28,29]$. Another effective way is to build a robust SEI to prevent Li metal from reacting with liquid electrolyte via in-situ reduction of sacrificial electrolyte additives (e.g., $\mathrm{LiNO}_{3}[30,31]$, vinyl carbonate [32], fluoroethylene carbonate [33], and $\mathrm{CsPF}_{6}$ [34]), or ex-situ construction of protective layers (e.g., $\mathrm{Li}_{3} \mathrm{PO}_{4}$ [35], $\mathrm{Cu}_{3} \mathrm{~N} /$ styrene-butadiene rubber [36], $\mathrm{Li}_{x} \mathrm{Si}$ alloy [37], and $\mathrm{Li}^{+}$affinity leaky film [38]). These SEI layers functioned as a passivation layer on the surface of Li metal can effectively inhibit the growth of Li dendrite $[39,40]$.

Although the above-discussed methods have made great progress in alleviating the drawbacks of LMA, the vertical growth of Li dendrite due to the "tip effect" of $\mathrm{Li}$ protrusion remains a big challenge, especially under high deposition capacities (Fig. 1a) [41]. Therefore, some different mechanisms have been proposed to regulate the horizontal growth of $\mathrm{Li}$ and thus suppress $\mathrm{Li}$ dendrite growth. For instance, the LiF-enriched SEI was used to achieve the horizontal growth of Li due to its high surface energy against $\mathrm{Li}$ metal that is favorable for Li-ion migration along the interphase $[42,43]$. The fine in-plane lattice matching between $\mathrm{Li}$ and the reduced graphene oxide (rGO) substrate also enables the epitaxial growth of planar Li layers on rGO substrate [44]. In addition, the parallelly aligned MXene $\left(\mathrm{Ti}_{3} \mathrm{C}_{2} \mathrm{~T}_{x}\right)$ layers with abundant fluorine terminations can induce the horizontal growth $\mathrm{Li}$ anodes [45]. However, these strategies are difficult to realize the overall and accurate regulation of Li deposition by governing $\mathrm{Li}$ nucleation, diffusion and horizontal growth mechanism.

Herein, we propose a novel Li nucleation-diffusiongrowth mechanism achieved by a hybrid interface layer consisting of Li-Sn alloy and $\mathrm{Li}_{3} \mathrm{~N}$ electrolyte (LS/LN) to comprehensively govern the horizontal deposition behavior of Li metal. The lithiophilic Li-Sn alloy contributes to the preferred nucleation of $\mathrm{Li}$ on the Li-Sn alloy sites. The $\mathrm{Li}_{3} \mathrm{~N}$ as a fast Li-ion conductor presents low Li-ion migration energy barriers, which enables the Li-ion horizontal migration along the LS/LN interface to the alloy sites. Benefiting from the synergistic effect of $\mathrm{Li}_{3} \mathrm{~N}$ and $\mathrm{Li}-$ $\mathrm{Sn}$ alloy, the horizontal deposition of $\mathrm{Li}$ is persistently achieved during the Li plating process, which effectively suppresses the $\mathrm{Li}$ dendrite growth and side reactions of $\mathrm{Li}$ metal with electrolyte (Fig. 1b). As a result, the LS/LN-Li symmetrical cell can stably cycle over $1600 \mathrm{~h}$ under a high current density of $5 \mathrm{~mA} \mathrm{~cm}^{-2}$ and deposition capacity of $5 \mathrm{~mA} \mathrm{~h} \mathrm{~cm}^{-2}$. The $\mathrm{LiFePO}_{4} \mid \mathrm{LS} / \mathrm{LN}-\mathrm{Li}$ full cell with a high cathode loading of $8.2 \mathrm{mg} \mathrm{cm}^{-2}$ exhibits much higher capacity retention (93.4\%) and CE (99.8\%) than that using bare $\mathrm{Li}$ metal $(64.8 \%$ and $45 \%)$. Besides, the capacity retentions of $\mathrm{LiNi}_{0.8} \mathrm{Co}_{0.1} \mathrm{Mn}_{0.1} \mathrm{O}_{2}$ using LS/LN-Li and bare $\mathrm{Li}$ are $79.1 \%$ and $23.0 \%$ after 200 cycles at $1 \mathrm{C}$, respectively. This work provides a novel mechanism to govern the horizontal deposition of Li metal, which not only solves the Li dendrite growth problem but also suppresses the side reactions between Li metal and electrolyte.

\section{EXPERIMENTAL SECTION}

\section{Preparation of LS/LN-Li foil}

The commercial Li foil with a thickness of $500 \mu \mathrm{m}$ was purchased from China Energy Lithium Co., Ltd. The LS/ LN layers with different thicknesses were constructed on the Li foil surface by radio frequency (RF) magnetron
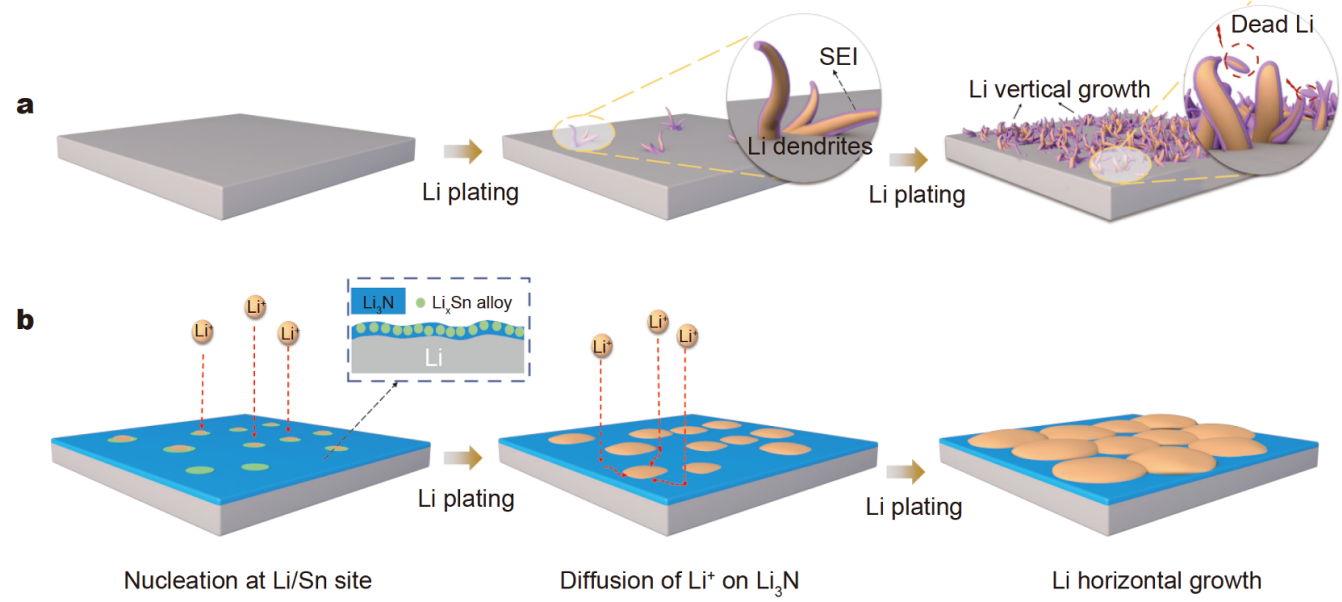

Figure 1 Schematic of Li plating behaviors on the (a) bare Li and (b) LS/LN-Li surface. 
sputtering (CK-450, Shenyang Pengcheng Vacuum Technology Co., Ltd.) using a Sn metal target with a diameter of $60 \mathrm{~mm}$ (99.99\%, Beijing Licheng Innovation Metal Materials Technology Co., Ltd.). The base pressure before sputtering in the chamber was $5 \times 10^{-4} \mathrm{~Pa}$, and the sputtering pressure was approximately $7 \mathrm{~Pa}$ controlled by a mixture atmosphere of $\mathrm{N}_{2}$ and $\operatorname{Ar}$ (1:1 by volume) with a total gas flow of $80 \mathrm{sccm}$. The sputtering power was set at $80 \mathrm{~W}$. The target-to-substrate distance was fixed at $6 \mathrm{~cm}$ and the rotation rate of the substrate was $20 \mathrm{r} \mathrm{min}^{-1}$. To obtain the uniform sputtering layers with different thicknesses, we adjust the sputtering time in the range of 10-30 min. It is noteworthy that all the substrate transfer processes were carried out through the glove box without exposure to air.

\section{Material characterizations}

The morphologies and element distributions of the samples were characterized by a field emission scanning electron microscope (FE-SEM, HITACH S4800, Japan) equipped with an energy-dispersive $\mathrm{X}$-ray spectroscope (EDS). The cross-section of LSLN-Li was cut by a focused ion beam (FIB) and observed on the FEI Scios. The valence state and chemical composition were tested by the X-ray photoelectron spectroscopy (XPS, PHI 5000 VersaProbe II). For both SEM and XPS measurements on Li metal after cycling, the disassembled lithium foils were rinsed with the 1,2-dimethoxyethane (DME) solution for $5 \mathrm{~min}$ to remove residual electrolyte and lithium salts and then dried in an Ar-filled glove box. The samples were sealed in a transfer vessel in an Ar-filled glovebox before being opened inside the chamber. The transmission electron microscopy (TEM) images were obtained using an FEI Tecnai G2 F30. In-situ optical microscopy was performed in a home-made optical cell model with transparent glass to monitor the morphology evolution during the plating/stripping process. The contact angle was tested with an MDTC-EQ-M07-01.

\section{Electrochemical measurements}

CR2032-type coin cells were assembled using Celgard 2500 as the separator in an Ar-filled glove box $\left(\mathrm{H}_{2} \mathrm{O}\right.$, $\left.<0.01 \mathrm{ppm} ; \mathrm{O}_{2},<0.01 \mathrm{ppm}\right)$. A LAND CT2001A testing system was used to measure the galvanostatic chargedischarge measurements. Electrochemical impedance spectroscopy (EIS) measurements were carried out on a VMP3 multichannel electrochemical station (Bio Logic Science Instruments, France) with a voltage amplitude of $10 \mathrm{mV}$ in a frequency range of $100 \mathrm{kHz}$ to $10 \mathrm{mHz}$. For $\mathrm{Li} \mid \mathrm{Li}$ symmetric cells, a total volume of $60 \mu \mathrm{L}$ of
$1.0 \mathrm{~mol} \mathrm{~L}^{-1}$ lithium bis(trifluoromethanesulfonyl)-imide (LiTFSI) in 1,3-dioxolane (DOL) and DME (1:1 by volume) with $2 \mathrm{wt} \% \mathrm{LiNO}_{3}$ as the additive was selected as the electrolyte, and bare $\mathrm{Li}$ or LS/LN-Li were used as electrodes. For the full cells, both the $\mathrm{LiFePO}_{4}$ (LFP) and $\mathrm{LiNi}_{0.8} \mathrm{Co}_{0.1} \mathrm{Mn}_{0.1} \mathrm{O}_{2}$ (NCM) cathode (12 mm diameter disk) were fabricated by a slurry coating method, in which the active material (LFP or NCM powder), binder (PVDF), and conductive agent (super $\mathrm{P}$ ) were mixed in a mass ratio of 8:1:1 with $N$-methyl-2-pyrrolidone (NMP) as a solvent, and then coated on the Al foil followed by 12 -h drying in a vacuum oven. Both ether-based electrolyte ( $1 \mathrm{~mol} \mathrm{~L}^{-1}$ LiTFSI in DOL/DME (1:1 by volume) with $2 \mathrm{wt} \% \mathrm{LiNO}_{3}$ ) with a voltage range of $2.4-4.0 \mathrm{~V}$ and conventional carbonate-based electrolyte $\left(1.0 \mathrm{~mol} \mathrm{~L}^{-1} \mathrm{li}\right.$ thium hexauorophosphate $\left(\mathrm{LiPF}_{6}\right)$ in ethylene carbonate (EC), diethyl carbonate (DEC) and dimethyl carbonate (DMC) (1:1:1 by volume)) in a voltage range of $2.4-4.2 \mathrm{~V}$ were employed in the Li|LFP full cells. For the Li|NCM full cells, the electrolyte used was $1.0 \mathrm{~mol} \mathrm{~L}^{-1} \mathrm{LiPF}_{6}$ in EC, DMC, and ethylmentyl carbonate (EMC) (1:1:1 by volume) with a voltage range of $2.8-4.3 \mathrm{~V}$. In general, the amount of electrolyte was $60 \mu \mathrm{L}$ in the full cells, unless otherwise stated (such as a lean electrolyte system).

\section{Computational method and models}

All calculations were carried out by using the projector augmented wave method in the framework of the density functional theory (DFT) [46], as implemented in the Vienna ab-initio Simulation Package (VASP). The generalized gradient approximation (GGA) and PerdewBurke-Ernzerhof (PBE) exchange function were used [46]. The plane-wave energy cutoff was set to $500 \mathrm{eV}$, and the Monkhorst-Pack method was employed for the Brillouin zone sampling [47]. The convergence criteria of energy and force calculations were set to $10^{-5} \mathrm{eV}$ per atom and $0.01 \mathrm{eV} \AA^{-1}$, respectively. A vacuum region of $15 \AA$ was applied to avoid interactions between the neighboring configurations [48]. DFT-D3 method was used to account for the van der Waals interactions between the organic molecule and metal surface. Here, the binding energies $E_{\mathrm{b}}$ were calculated by the energy difference of the system after and before adsorption:

$E_{\mathrm{b}}=E_{\mathrm{Li}-\mathrm{sub}}-E_{\mathrm{Li}}-E_{\mathrm{sub}}$,

where $E_{\mathrm{b}}, E_{\mathrm{Li} \text {-sub }}$, and $E_{\text {sub }}$ represent the DFT energy of the Li-adsorbed substrate, the energy of an isolated Li atom, and the energy of the substrate, respectively.

The energy barriers for Li diffusion on different surfaces were calculated by the nudged elastic band (NEB) 
method to evaluate their dynamic properties [49].

\section{RESULTS AND DISCUSSION}

The LS/LN layer was in-situ fabricated on the Li metal anode via the RF magnetron sputtering using Sn metal target under a mixture atmosphere of $\mathrm{N}_{2}$ and Ar. The SEM images present that a compact and conformal film with a thickness of $1.3 \mu \mathrm{m}$ composed of tightly stacked nanoparticles is homogeneously deposited on the Li metal surface (Fig. 2a, b and d). Obviously, the formation of the hybrid film is accompanied by the color change from silver to black on the Li-metal surface. The EDS analysis confirms the presence of both $\mathrm{N}$ and Sn elements on the LS/LN-Li surface (Fig. S1). The corresponding elemental mappings show that $\mathrm{Sn}$ and $\mathrm{N}$ elements are uniformly distributed on the LS/LN film surface (Fig. 2c). The TEM and selective area electron diffraction (SAED) pattern of the LS/LN layer present that nanocrystals with a width range of 5-10 nm are formed in the LS/LN layer. Several sets of lattice fringes with a lattice spacing of $0.224 \mathrm{~nm}$ can be clearly observed, which is ascribed to the (022) plane of $\mathrm{Li}_{7} \mathrm{Sn}_{2}$. XPS was applied to further characterize the composition and surface chemistry of the LS/LN film. From the XPS full spectra in Fig. S2, the signals of N, Sn, and Li elements were observed as expected. The high $\mathrm{O}$ content and trace $\mathrm{C}$ content may result from the exposure of LS/LN-Li to air during the sample transfer process for examination. The high-resolution $\mathrm{Sn} 3 \mathrm{~d}_{5 / 2}$ XPS at $484.0 \mathrm{eV}$ (Fig. $2 \mathrm{~g}$ ) is indicative of Li-Sn alloy, which can be further demonstrated by the $\mathrm{Li} 1 \mathrm{~s}$ peak at $56.7 \mathrm{eV}$ (Fig. 2i) [50-53]. The peak at $397.0 \mathrm{eV}$ in $\mathrm{N}$ 1s spectra (Fig. 2h) is ascribed to the $\mathrm{N}-\mathrm{Li}$ bond of $\mathrm{Li}_{3} \mathrm{~N}$, corresponding to the $\mathrm{Li} 1 \mathrm{~s}$ peak at $55.8 \mathrm{eV}$ (Fig. 2i) [54-56]. Besides, two other peaks of $\mathrm{N}$ 1s spectra with high binding energies at 399.3 and $400.9 \mathrm{eV}$ represent the $\mathrm{N}-\mathrm{H}$ or interstitial $\mathrm{N}$ species and $\mathrm{N}-\mathrm{O}$ band, respectively $[57,58]$. It is worth noting that the $\mathrm{N} 1 \mathrm{~s}$ shows a peak at $394.9 \mathrm{eV}$ that is related to substoichiometric nitride
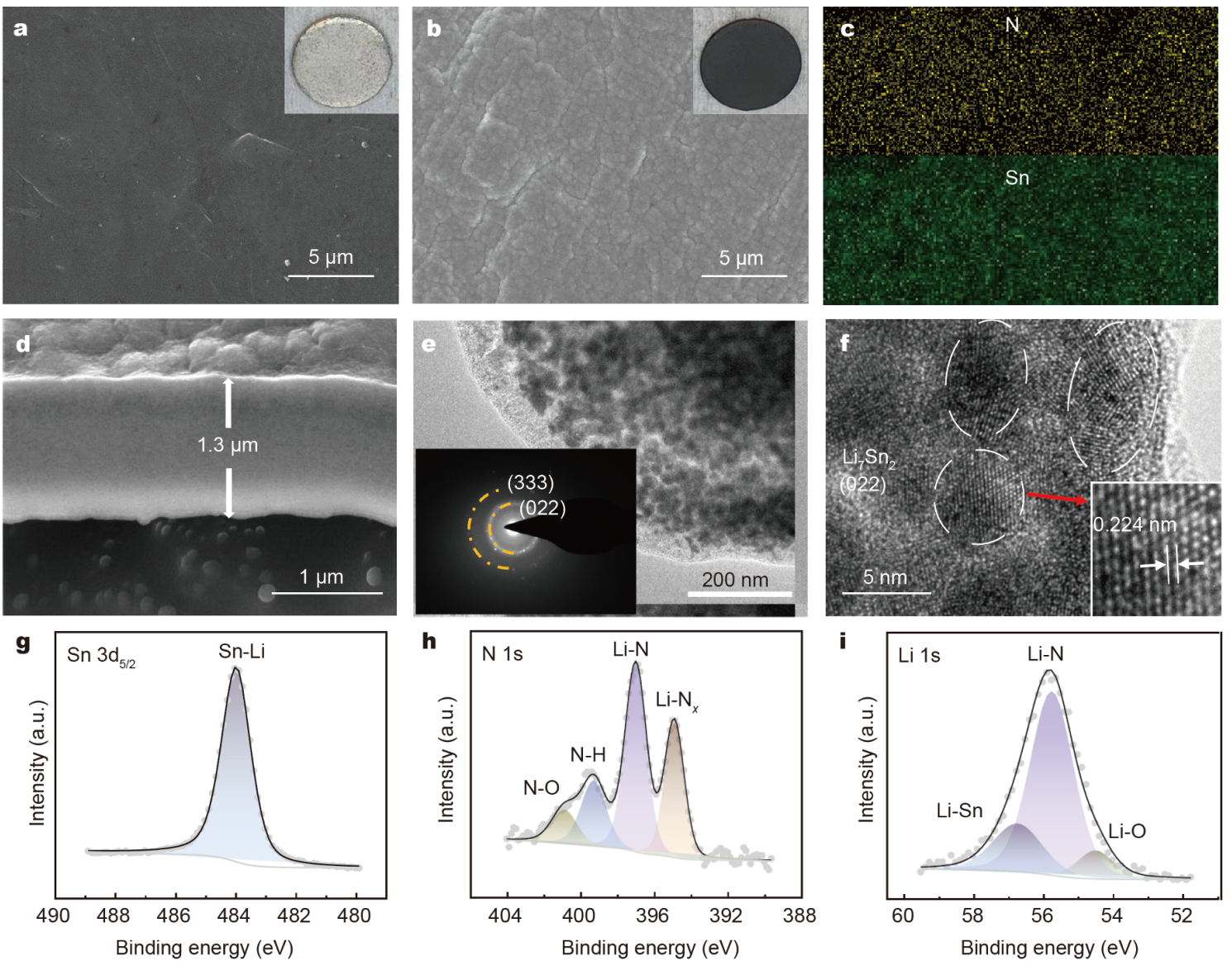

Figure 2 Top-view SEM images of (a) bare Li and (b) LS/LN-Li. Insets are the photographs of bare Li and LS/LN-Li. (c) EDS elemental mapping images of the LS/LN-Li. (d) Cross-sectional FIB SEM image of LS/LN-Li. (e) TEM images of LS/LN film (SAED in inset), and (f) HRTEM image. (g) Sn $3 d_{5 / 2}$, (h) N 1s, and (i) Li 1s XPS spectra of LS/LN-Li after 14-min sputtering. 
$\left(\operatorname{LiN}_{x}\right)$, which may be formed in the preparation of nitrides by thin-film deposition $[59,60]$. According to the above characterizations, it can be concluded that the sputtered LS/LN film is composited of $\mathrm{Li}_{7} \mathrm{Sn}_{2}$ alloy and $\mathrm{Li}_{3} \mathrm{~N}$ electrolyte. In addition, the LS/LN film presents much more favorable wettability with electrolyte than bare Li (Fig. S3), indicating a superior electrolyte affinity (Table S1). The improved interfacial wettability with electrolyte is beneficial to eliminating the difference in $\mathrm{Li}$ ion concentration on the electrode surface and inducing the uniform distribution of $\mathrm{Li}$ ions [61].

The thickness of the LS/LN layer was optimized by controlling the sputtering times of 10,20 (the sample discussed in the text), and $30 \mathrm{~min}$. As shown in Fig. $2 \mathrm{~d}$ and Fig. S4, the surface morphologies of the LS/LN films with different sputtering times are similar, but the thickness increases with prolonging sputtering time. The most excellent cycling stability of $\mathrm{Li}$ symmetric cell is achieved by 20 -min-sputtered Li electrode (Fig. $3 \mathrm{~b}$ and Fig. S5). Therefore, the 20-min-sputtered LS/LN-Li was selected for further measurements and characterizations in this work. Li stripping/plating measurements of symmetric cells using bare $\mathrm{Li}$ and $\mathrm{LS} / \mathrm{LN}-\mathrm{Li}$ anode were performed to compare their long-term cycling stabilities.
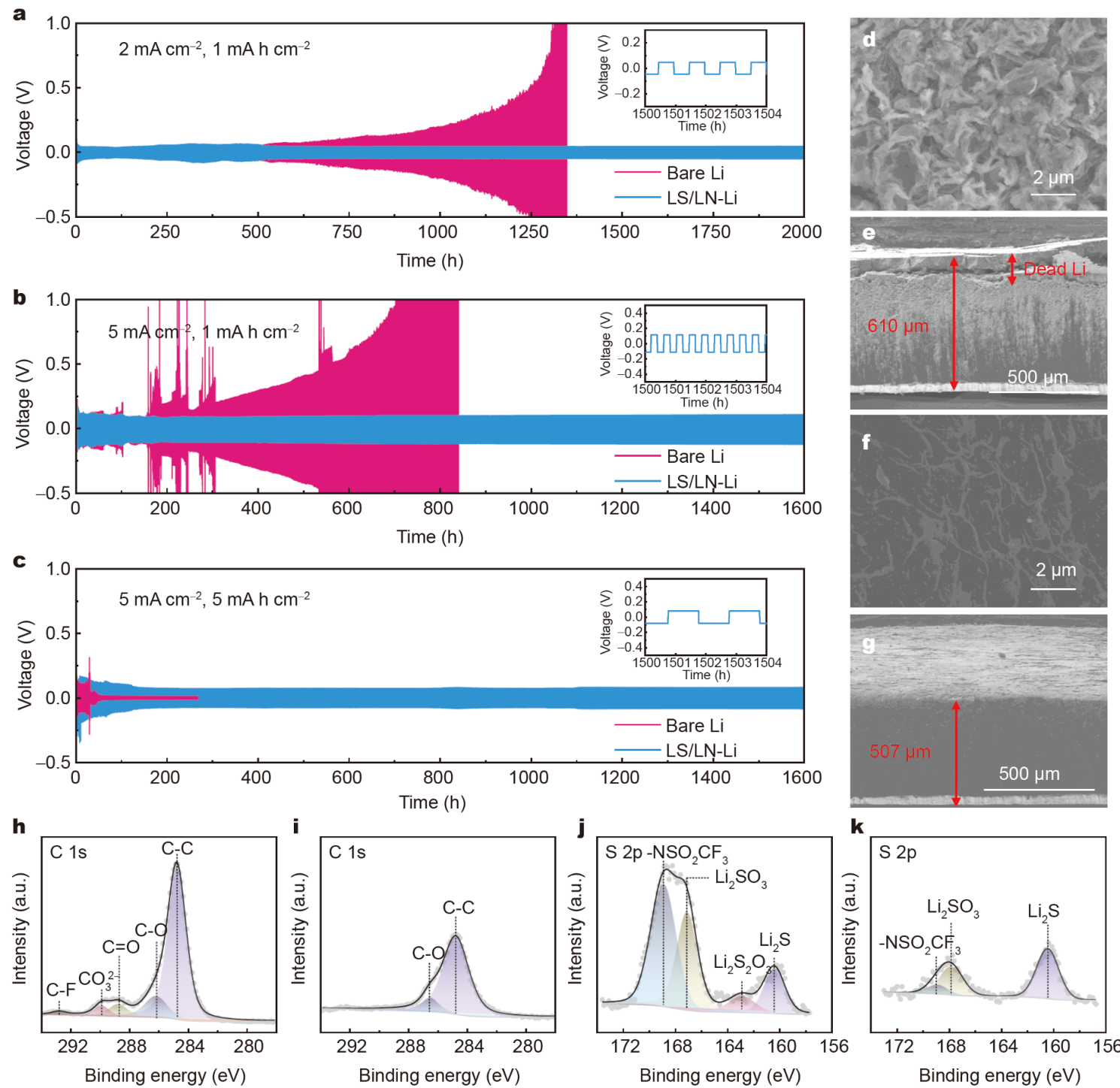

Figure 3 Voltage-time curves of Li plating/stripping and enlarged voltage curves in bare Li and LS/LN-Li symmetric cells at different current densities and deposition capacities: (a) $2 \mathrm{~mA} \mathrm{~cm}^{-2}$ and $1 \mathrm{~mA} \mathrm{~h} \mathrm{~cm}^{-2}$, (b) $5 \mathrm{~mA} \mathrm{~cm}^{-2}$ and $1 \mathrm{~mA} \mathrm{~h} \mathrm{~cm}^{-2}$, (c) $5 \mathrm{~mA} \mathrm{~cm}^{-2}$ and $5 \mathrm{~mA} \mathrm{~h} \mathrm{~cm}^{-2}$. Top-view and cross-section SEM images of (d, e) bare Li and (f, g) LS/LN-Li anodes in symmetric cells at $5 \mathrm{~mA} \mathrm{~cm}^{-2} \mathrm{with}^{\mathrm{mA} \mathrm{h} \mathrm{cm}} \mathrm{m}^{-2}$ after $100 \mathrm{cycles}$. (h, i) $\mathrm{C} 1 \mathrm{~s}$

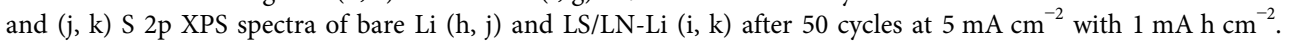


At a current density of $2 \mathrm{~mA} \mathrm{~cm}^{-2}$ with a deposition capacity of $1 \mathrm{~mA} \mathrm{~h} \mathrm{~cm}^{-2}$, the overpotential of bare Li symmetric cell shows an obvious increase from $500 \mathrm{~h}$ and finally reaches $4 \mathrm{~V}$ after 1350 -h cycling, which is caused by the formation of Li dendrite and accumulated dead $\mathrm{Li}$ on the Li anode surface (Fig. 3a) [62,63]. In sharp contrast, the cell with LS/LN-Li anode displays a long cycling life up to $2000 \mathrm{~h}$ with a low overpotential of $45 \mathrm{mV}$, suggesting that Li dendrites are effectively suppressed. As the current density increases to $5 \mathrm{~mA} \mathrm{~cm}^{-2}$, the overpotential of bare Li symmetric cell fluctuates wildly and increases rapidly after $150 \mathrm{~h}$ (Fig. 3b), while the LS/LN-Li symmetric cell can cycle stably for $1600 \mathrm{~h}$ without the increase of voltage polarization. Furthermore, when $\mathrm{Li}$ deposition capacity is increased to $5 \mathrm{~mA} \mathrm{~h} \mathrm{~cm}$ at a high current density of $5 \mathrm{~mA} \mathrm{~cm}^{-2}$, the bare Li symmetric cell experiences an internal short circuit caused by lithium dendrites after only $32 \mathrm{~h}$. On the contrary, the LS/LN-Li symmetric cell presents a superior cycling lifespan for $1600 \mathrm{~h}$ (Fig. 3c), which is remarkably better than the previously reported results (Table S2). The EIS spectra of symmetric cells with different cycles display that the LS/ LN-Li symmetric cell shows larger impedance than that of bare Li before cycling because of the sputtered LS/LN layer, which explains the larger overpotential in symmetrical cell during the initial cycles (Fig. S6). However, the impedance of LS/LN-Li tends to be stable gradually in the following cycles, while that of bare Li keeps increasing, especially after 200 cycles. This result further confirms that the LS/LN-Li symmetric cells remain stable during long-term cycles. In addition, a $\mathrm{Sn}_{x} \mathrm{~N}$ interfacial layer was sputtered on the surface of $\mathrm{Cu}$ foil under the same conditions (Fig. S7). The $\mathrm{Li}^{-} \mathrm{Sn}_{x} \mathrm{~N} / \mathrm{Cu}$ cell exhibits a significantly improved $\mathrm{CE}$ due to the protection of LS/LN layer formed by the reaction of $\mathrm{Sn}_{x} \mathrm{~N}$ with $\mathrm{Li}$ ions (Fig. S8). The excellent cycling stability indicates that the LS/LN layer can achieve the dendrite-free LMA.

The surface morphologies of bare $\mathrm{Li}$ and LS/LN-Li anode after cycling were examined to understand the role of the LS/LN layer. As shown in Fig. 3d and Fig. S9a, the bare $\mathrm{Li}$ anode shows a rough and fluffy surface completely covered with mossy $\mathrm{Li}$ and cracks, indicating that the fragile electrolyte-induced SEI layer fails to withstand the uncontrolled dendrite growth caused by uneven vertical deposition of Li during long-term plating/stripping process. These moss-like Li dendrites with a high surface area would exacerbate the side reactions with the liquid electrolyte, leading to increased electrolyte consumption and dead Li formation [64]. In sharp contrast, smooth and dense Li deposition morphology with interconnected li- thium wafers is observed on the surface of $\mathrm{LS} / \mathrm{LN}-\mathrm{Li}$ anode (Fig. 3f and Fig. S9b). In addition, the volume change of the electrode was also measured by the SEM. As shown in Fig. 3e and g, abundant dead Li is formed and fractured from the bare Li electrode, and the thickness increases to $610 \mu \mathrm{m}$. In sharp contrast, the LS/LN-Li electrode still keeps intact without obvious thickness increase, suggesting that the LS/LN layer can induce dense $\mathrm{Li}$ deposition. The stripping behavior of the bare $\mathrm{Li}$ and LS/LN-Li presents that a large number of pit areas attributed to the localized dissolution of $\mathrm{Li}$ metal during $\mathrm{Li}$ stripping are formed on the bare Li surface (Fig. S10). Those pits cause an unevenly distributed electric field on the $\mathrm{Li}$ anode and further render uneven Li plating/stripping. Interestingly, the cycled LS/LN-Li anode maintains a uniform and intact surface without any cracks and voids due to uniform Li stripping, which can reduce the side reactions with the electrolyte. The in-situ optical microscopy was performed to monitor the morphology evolution induced by the LS/LN layer (Fig. S11). A few tiny dendrites were observed on the surface of the bare $\mathrm{Li}$ electrode, but the LS/LN-Li electrode showed a smooth surface morphology without any dendrites after $1 \mathrm{~h}$. Numerous moss-like dendrites continuously arose on the bare Li surface, while the LS/LN-Li anode still maintained a homogeneous and compact surface even after $5 \mathrm{~h}$. The differences in morphology evolution fully suggest that the LS/LN composite film can effectively inhibit the growth of $\mathrm{Li}$ dendrite and regulate the uniform deposition of $\mathrm{Li}$ ion. Moreover, the XPS and EDS spectra present that the cycled bare Li and LS/LN-Li consist of quite a different chemical composition of the SEI layer (Figs S12 and S13). The contents of $\mathrm{C}, \mathrm{O}, \mathrm{S}$, and $\mathrm{F}$ elements derived from the reaction products of the electrolyte with $\mathrm{Li}$ on the surface of bare $\mathrm{Li}$ is significantly higher than that of $\mathrm{LS} / \mathrm{LN}-\mathrm{Li}$, indicating the suppressed side reactions achieved by LS/ LN layer. As shown in Fig. 3h, i, the C 1s spectra of cycled bare $\mathrm{Li}$ presents five binding states at 284.78, 286.21, $288.79,289.91$, and $292.83 \mathrm{eV}$, corresponding to C-C, $\mathrm{C}-\mathrm{O}, \mathrm{C}=\mathrm{O}, \mathrm{CO}_{3}{ }^{2-}$ and $\mathrm{C}-\mathrm{F}$ groups, respectively, which are mainly derived from the decomposition products of the organic solvents and LiTFSI [65]. However, for the cycled LS/LN-Li, only two peaks ascribed to C-C and C$\mathrm{O}$ were detected and the peaks intensity of $\mathrm{C}-\mathrm{C}$ and $\mathrm{C}-\mathrm{O}$ weakened compared with cycled bare $\mathrm{Li}$, proving the significant suppression of the side reactions of LS/LN-Li with electrolyte. This result can be further validated by S 2p, N 1s, and F 1s spectra (Fig. 3j, k and Fig. S14), where fewer decomposition products are detected on the surface of LS/LN-Li [66-68]. Therefore, the LS/LN layer not only 
completely suppresses the Li dendrite growth and alleviate the volume variation of the $\mathrm{Li}$ electrode, but also greatly decreases the side reaction between Li metal and electrolyte.

The morphology evolutions of Li deposition on bare Li and LS/LN-Li anode surface were monitored to visualize the nucleation, diffusion, and growth processes of $\mathrm{Li}$ metal. With a low deposition capacity of $0.2 \mathrm{~mA} \mathrm{~h} \mathrm{~cm}^{-2}$, plenty of disk-shaped Li spots are evenly distributed over the surface of the LS/LN layer. Whereas, local agglomerative Li nucleation occurs on the inhomogeneous surface of bare Li (Fig. 4a, e, i, and Fig. S15a). As the deposition capacity gradually increases from 0.2 to $1 \mathrm{~mA} \mathrm{~h} \mathrm{~cm}{ }^{-2}$, numerous uneven and needle-like Li dendrites are deposited on the surface of bare Li (Fig. 4 b, c and Fig. S15b, c). When the deposition capacity increases to $3 \mathrm{~mA} \mathrm{~h} \mathrm{~cm}$, entangled Li dendrites were clearly observed, covering almost the entire surface of bare $\mathrm{Li}$ (Fig. 4d and Fig. S15d). In sharp contrast, the initial deposited Li disks on LS/LN-Li keep growing horizontally, showing an increasing diameter of Li disks (Fig. 4f, j, g, k). Finally, Li disks with ever-increasing diameter finally merge together to form a dense and flat $\mathrm{Li}$ continuum with visible grain boundaries in the horizontal plane (Fig. 4h, 1). In addition, it is worth noting that the deposited Li on LS/LN-Li possesses a columnar morphology while that on bare Li presents a filament-like morphology (Fig. S16), which further demonstrates that $\mathrm{Li}$ grows horizontally on the LS/LN surface, neither vertically nor dendriticly. Therefore, the LS/LN layer achieves the
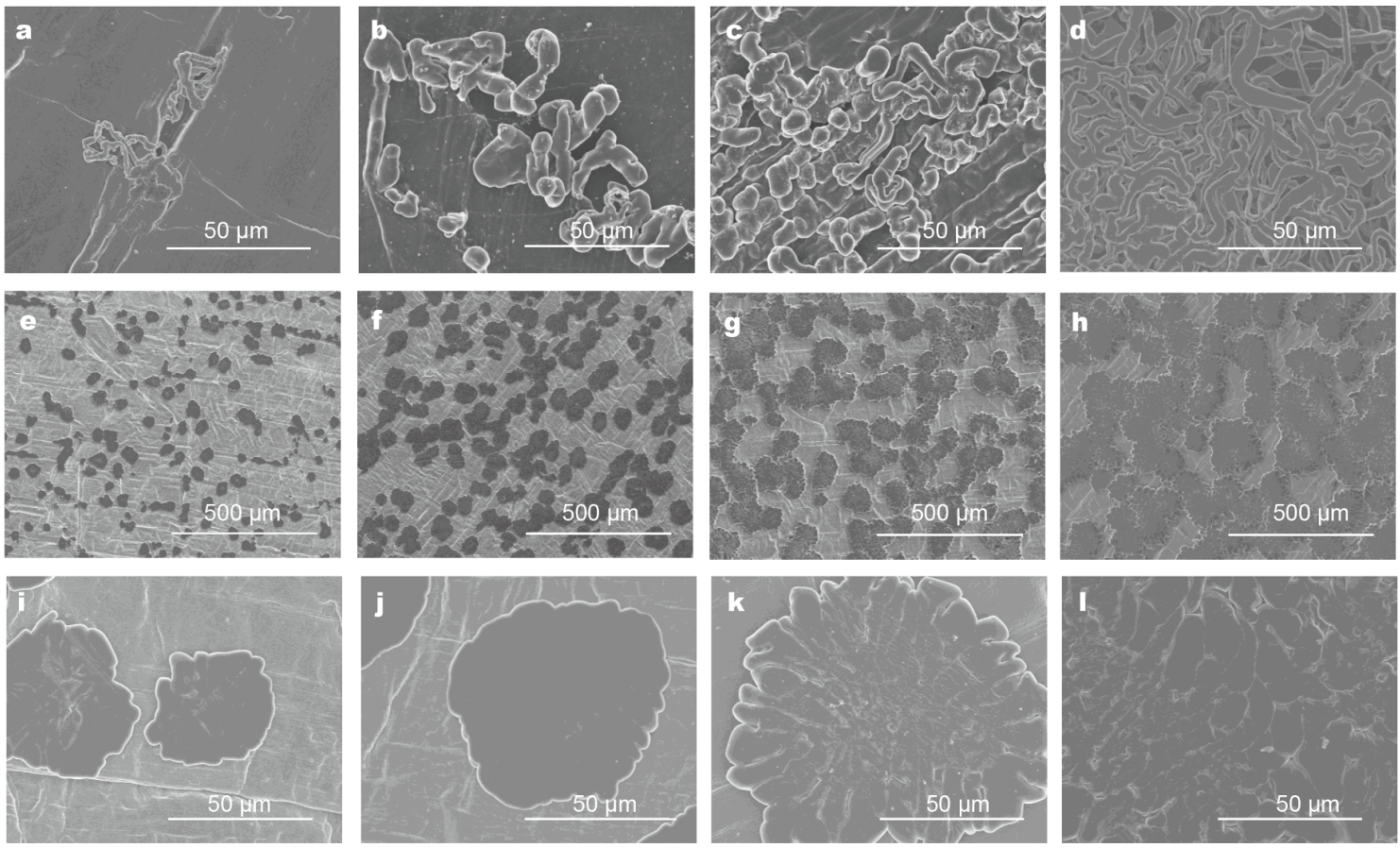

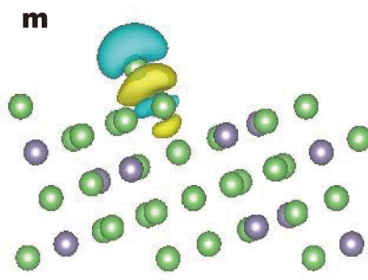

$\mathrm{Li}_{7} \mathrm{Sn}_{2}: E_{\mathrm{b}}=-1.92 \mathrm{eV}$

$\mathrm{Li}$

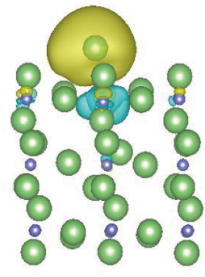

$\mathrm{Li}_{3} \mathrm{~N}: E_{\mathrm{b}}=-1.18 \mathrm{eV}$

$\mathrm{Sn}$
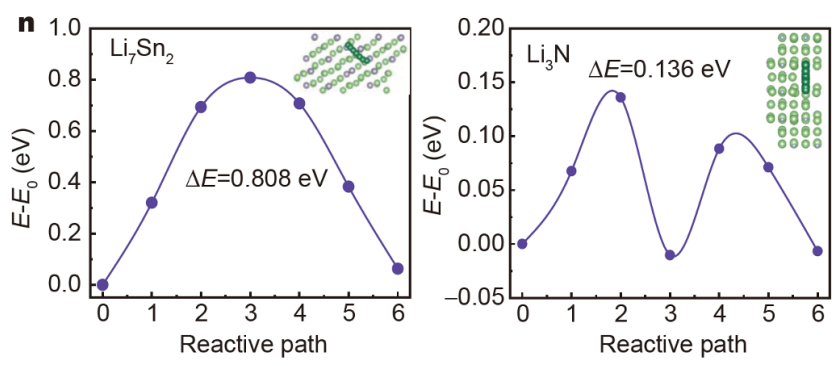

Adsorbed L

Figure 4 Top-view SEM images of (a-d) bare Li and (e-l) LS/LN-Li in symmetric cells with different deposition capacities: (a, e, i) $0.2 \mathrm{~mA} \mathrm{~h} \mathrm{~cm}^{-2}$,

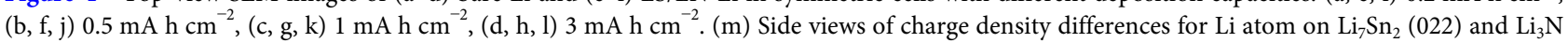
(100) surfaces. (n) The diffusion energy barriers of $\mathrm{Li}$ on the $\mathrm{Li}_{7} \mathrm{Sn}_{2}(022)$ and $\mathrm{Li}_{3} \mathrm{~N}(100)$ surfaces. The insets show the $\mathrm{Li}$ diffusion paths. 
overall regulation for the $\mathrm{Li}$ nucleation, diffusion, and horizontal growth, and effectively inhibits the formation of Li dendrite. The DFT simulations were conducted to reveal the mechanism of $\mathrm{Li}$ nucleation, diffusion, and horizontal growth achieved by LS/LN layer. The facets of $\mathrm{Li}_{7} \mathrm{Sn}_{2}$ and $\mathrm{Li}_{3} \mathrm{~N}$ used here are (022) and (100), respectively, because they are the most exposed and common lattice planes [69]. The $\mathrm{Li}_{7} \mathrm{Sn}_{2}$ (022) surface exhibits larger binding energy $(-1.92 \mathrm{eV})$ than that of the $\mathrm{Li}_{3} \mathrm{~N}(100)$ surface $(-1.18 \mathrm{eV})$, which indicates a stronger interaction between $\mathrm{Li}_{7} \mathrm{Sn}_{2}$ and Li (Fig. $4 \mathrm{~m}$ ). The lithiophilic Li-Sn alloy could provide abundant nucleation sites and favor for homogeneous nucleation of $\mathrm{Li}[70,71]$. More importantly, the difference in binding energy with Li leads to the selective nucleation of $\mathrm{Li}[72,73]$. Thus, the higher binding energy of Li-Sn alloy results in the preferential nucleation of Li on the Li-Sn alloy sites during Li plating. The charge density difference further certifies this result. The yellow and cyan isosurfaces represent the charge accumulation region and charge depletion, respectively. $\mathrm{Li}$ atom has a strong interaction with $\mathrm{Sn}$ of $\mathrm{Li}_{7} \mathrm{Sn}_{2}$, and it acts as an electron donor and transfers the electron to $\mathrm{N}$ of $\mathrm{Li}_{3} \mathrm{~N}$. The increased interaction between $\mathrm{Li}$ and $\mathrm{Sn}$ contributes to its higher binding energy. The diffusion energy barriers of $\mathrm{Li}$ on $\mathrm{Li}_{7} \mathrm{Sn}_{2}$ and $\mathrm{Li}_{3} \mathrm{~N}$ were calculated by the NEB method to evaluate their dynamic properties (Fig. $4 \mathrm{n}$ ). According to the DFT calculations, the $\mathrm{Li}_{3} \mathrm{~N}$ with high ionic conductivity exhibits much lower diffusion energy barrier $(0.136 \mathrm{eV})$ than $\mathrm{Li}_{7} \mathrm{Sn}_{2}(0.808 \mathrm{eV})[74-$ 76]. This result indicates that the migration of $\mathrm{Li}$ ions in $\mathrm{Li}_{3} \mathrm{~N}$ is much easier than that in $\mathrm{Li}_{7} \mathrm{Sn}_{2}$, which promotes the horizontal migration of $\mathrm{Li}$ ions across the $\mathrm{LS} / \mathrm{LN}$ layer to the nucleation sites of Li-Sn alloy $[77,78]$. Benefiting from the synergistic effect of preferential nucleation on Li-Sn alloy and highly efficient Li-ion transport in $\mathrm{Li}_{3} \mathrm{~N}$, the horizontal deposition of $\mathrm{Li}$ is achieved during $\mathrm{Li}$ plating, which suppresses the vertical growth of Li dendrite. Therefore, the combined Li plating morphologies and DFT calculations show that $\mathrm{Li}-\mathrm{Sn}$ alloy and $\mathrm{Li}_{3} \mathrm{~N}$ cooperatively guide the horizontal growth of $\mathrm{Li}$ metal.

To further identify the role of $\mathrm{Li}-\mathrm{Sn}$ alloy and $\mathrm{Li}_{3} \mathrm{~N}$ component for inducing the horizontal deposition of $\mathrm{Li}$, the $\mathrm{Sn}-\mathrm{Li}$ anode was also prepared by magnetron sputtering using Sn metal target under an atmosphere of Ar. A uniform and dense Li-Sn alloy layer with a thickness of around $1.5 \mu \mathrm{m}$ is formed on the surface Li metal by the reaction of Li with Sn (Figs S17 and S18). Similarly, the planar plating and horizontal growth of $\mathrm{Li}$ on the surface of Sn-Li anode is also observed when the deposition capacity is lower than $1 \mathrm{~mA} \mathrm{~h} \mathrm{~cm}{ }^{-2}$ (Fig. S19). However, when the deposition capacity is increased to $3 \mathrm{~mA} \mathrm{~h} \mathrm{~cm}{ }^{-2}$, the deposited $\mathrm{Li}$ presents dendritic and porous morphology like that on the bare Li anode. The above results indicate that the nucleation and diffusion of $\mathrm{Li}$ ions simultaneously affect the $\mathrm{Li}$ deposition behavior. The slower $\mathrm{Li}$-ion migration of $\mathrm{Li}$-Sn alloy than $\mathrm{Li}_{3} \mathrm{~N}$ restricts the horizontal deposition of $\mathrm{Li}$ under large deposition capacity. As a result, the $\mathrm{Sn}-\mathrm{Li}$ anode symmetrical cell presents a continuous voltage increase after only $300 \mathrm{~h}$ at $5 \mathrm{~mA} \mathrm{~cm}^{-2}$ with $1 \mathrm{~mA} \mathrm{~h} \mathrm{~cm}$ (Fig. S20) and higher interfacial impedance than $\mathrm{LS} / \mathrm{LN}-\mathrm{Li}$ symmetrical cell (Fig. S21). Therefore, $\mathrm{Li}_{3} \mathrm{~N}$ plays an important role in facilitating Li-ion transport at the hybrid interface for the horizontal growth of Li.

The LS/LN-Li anode was explored in full cells by coupling with $\mathrm{LiFePO}_{4}$ (LFP) and $\mathrm{LiNi}_{0.8} \mathrm{Co}_{0.1} \mathrm{Mn}_{0.1} \mathrm{O}_{2}$ (NCM811) cathodes. With a high-loading $\left(8.2 \mathrm{mg} \mathrm{cm}^{-2}\right)$ LFP cathode and flooded electrolyte, the discharge capacity of bare Li|LFP full cell decays from 143.8 to 93.2 $\mathrm{mA} \mathrm{h} \mathrm{g}^{-1}$ accompanied by the rapid decline in $\mathrm{CE}$ (45\%) after 1000 cycles, while LS/LN-Li|LFP cell maintains a high discharge specific capacity of $133.7 \mathrm{~mA} \mathrm{~h} \mathrm{~g}^{-1}$ with a capacity retention rate of $93.4 \%$ and a high CE of 99.8\% (Fig. 5a). The capacity decay and reduced CE in the bare Li|LFP cell can be attributed to active Li loss and electrolyte consumption due to the severe side reactions of moss-like Li dendrite with the electrolyte [79]. The extended cycle life also proves that the LS/LN film can persistently protect the $\mathrm{Li}$ metal from the electrolyte corrosion and inhibit $\mathrm{Li}$ dendrite formation during long cycling. Under lean electrolyte conditions $\left(10 \mu \mathrm{L} \mathrm{mA} \mathrm{h}^{-1}\right.$, $13.8 \mathrm{mg} \mathrm{cm}^{-2}$ ), the bare Li|LFP cell suffers from severe capacity deterioration after only 50 cycles, and its capacity is only $120.6 \mathrm{~mA} \mathrm{~h} \mathrm{~g}^{-1}$ after 100th cycles. On the contrary, the LS/LN-Li|LFP cell still delivers a high capacity of $143.8 \mathrm{~mA} \mathrm{~h} \mathrm{~g}^{-1}$ with negligible capacity fading after 100 cycles (Fig. 5b). In addition, we further tested the electrochemical performance of full cells in the commercial carbonate-based electrolyte. It can be seen that the LS/ LN-Li|LFP cell displays better stability than bare Li|LFP cell both with low-loading $\left(2.4 \mathrm{mg} \mathrm{cm}^{-2}\right)$ and high-loading $\left(7.5 \mathrm{mg} \mathrm{cm}^{-2}\right.$ ) cathodes (Fig. S22). Furthermore, the LS/LN-Li|NCM811 cells deliver capacities of 141 and $118.5 \mathrm{~mA} \mathrm{~h} \mathrm{~g}^{-1}$ at a high rate of 5 and $10 \mathrm{C}$, respectively (Fig. 5c), which are higher than that of bare Li|NCM811 cell (133.2 and $108.5 \mathrm{~mA} \mathrm{~h} \mathrm{~g}^{-1}$ ). In addition, the initial discharge capacity of the LS/LN-Li|NCM811 cell is $196.7 \mathrm{~mA} \mathrm{~h} \mathrm{~g}^{-1}$ in the $0.1 \mathrm{C}$ activation process and still retains $136.5 \mathrm{~mA} \mathrm{~h} \mathrm{~g}^{-1}$ with a capacity retention of $79.1 \%$ after 200 cycles at $1 \mathrm{C}$. However, the bare Li|NCM811 cell 

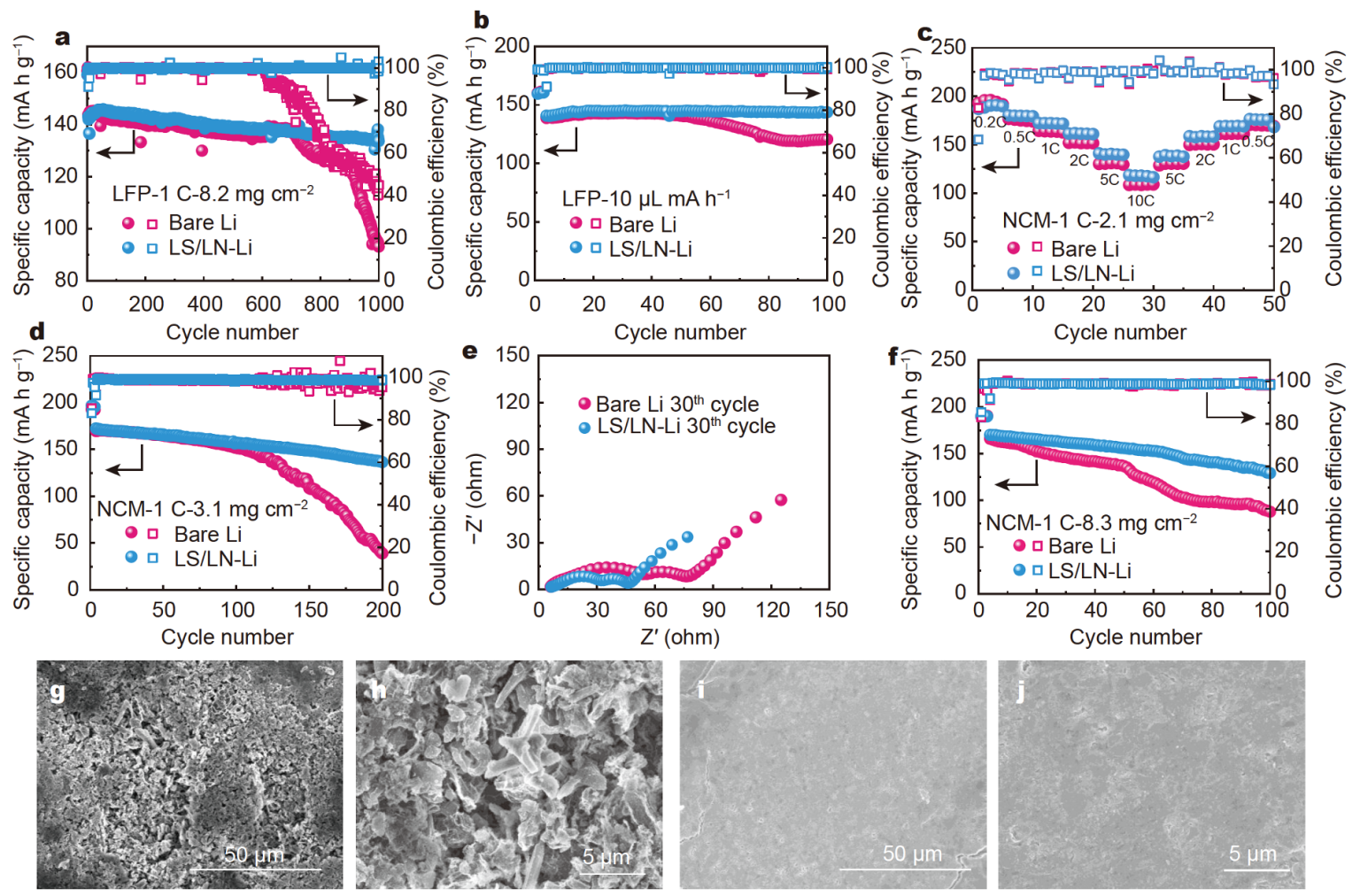

Figure 5 Cycling performances of Li|LFP full cells at $1 \mathrm{C}$ (a) with LFP loading of $\sim 8.2 \mathrm{mg} \mathrm{cm}^{-2}$ and (b) under lean electrolyte of $10 \mu \mathrm{L} \mathrm{mA} \mathrm{h}$. (c) Rate capabilities of Li|NCM full cells from 0.2 to $10 \mathrm{C}$. (d, f) Cycling performances of Li|NCM full cells with the NCM loading of $\sim 3.1$ and $\sim 8.3 \mathrm{mg} \mathrm{cm}^{-2}$ at $1 \mathrm{C}$. Solid symbol: specific capacity; open symbol: coulombic efficiency. (e) EIS spectra of Li|NCM full cells after 30 cycles. Top-view SEM images of $(g, h)$ bare Li and $(i, j)$ LSLN-Li anode after 100 cycles in Li|NCM full cells.

shows a quite poor cycling performance and its retention capacity is only $39 \mathrm{~mA} \mathrm{~h} \mathrm{~g}^{-1}$ after 200 cycles with a low capacity retention of $23.0 \%$ (Fig. $5 \mathrm{~d}$ ). In addition, the CE of LS/LN-Li|NCM cell remains stable, while that of bare Li|NCM811 cell starts to fluctuate after 112 cycles, proving that the LS/LN layer can reduce the loss of active Li. According to the charge/discharge voltage profiles, smaller overpotential can be observed in LS/LN-Li| NCM811 cell after 200 cycles due to the stable structure of LS/LN-Li and lower interfacial resistance (Fig. 5e and Fig. S23). The surface morphologies of LS/LN-Li and bare $\mathrm{Li}$ after 100 cycles present that a rough surface with massive needle-like $\mathrm{Li}$ is observed for bare Li anode, while the LSLN-Li anode remains a compact and smooth surface without any cracks and dendrites (Fig. $5 \mathrm{~g}-\mathrm{j}$ ). The difference in cycle stability becomes more dramatic with a higher loading of $8.3 \mathrm{mg} \mathrm{cm}^{-2}$ (Fig. $5 \mathrm{f}$ and Fig. S24). The LS/LN-Li|NCM811 cell displays a higher capacity of $129.1 \mathrm{~mA} \mathrm{~h} \mathrm{~g}^{-1}$ as well as an improved capacity retention of $75.9 \%$, in comparison with $87.8 \mathrm{~mA} \mathrm{~h} \mathrm{~g}^{-1}$ with only $52.9 \%$ capacity retention for the bare Li|NCM811 cell.
The significantly improved performance of the full cells with the LS/LN anode demonstrates that the Li horizontal deposition achieved by the LS/LN substrate can effectively suppress the Li dendrite growth and reduce the side reaction of Li with electrolyte.

\section{CONCLUSIONS}

In summary, a novel Li nucleation-diffusion-horizontal growth mechanism achieved by a $\mathrm{Li}-\mathrm{Sn}$ alloy/Li ${ }_{3} \mathrm{~N}$ (LS/ $\mathrm{LN}$ ) hybrid substrate is proposed to accurately govern the horizontal deposition behavior of Li metal, which effectively suppresses the Li dendrite formation and protects Li metal from electrolyte corrosion. The Li-Sn alloy with excellent lithiophilic nature provides uniform Li nucleation sites, and meanwhile the $\mathrm{Li}_{3} \mathrm{~N}$ with high $\mathrm{Li}$-ion conductivity and low Li-ion migration energy barriers ensures the highly efficient Li-ion transport along the LS/ LN surface. With the synergistic effect of the two components, $\mathrm{Li}$ ions are preferred to nucleate on the $\mathrm{Li} / \mathrm{Sn}$ alloy, and then $\mathrm{Li}_{3} \mathrm{~N}$ efficiently transports $\mathrm{Li}$ ions to the nucleation sites to achieve horizontal deposition of $\mathrm{Li}$ 
during $\mathrm{Li}$ plating, thus preventing the formation of $\mathrm{Li}$ dendrite. As a result, the LS/LN-Li symmetric cells can achieve long-term cycling over $1600 \mathrm{~h}$ under a high current density of $5 \mathrm{~mA} \mathrm{~cm}^{-2}$ and high deposition capacity of $5 \mathrm{~mA} \mathrm{~h} \mathrm{~cm}^{-2}$. Both high-loading LFP $\left(8.2 \mathrm{mg} \mathrm{cm}^{-2}\right)$ and NCM811 cathodes $\left(8.3 \mathrm{mg} \mathrm{cm}^{-2}\right)$ married with LS/LN-Li anode achieve excellent cycling performance at $1 \mathrm{C}$. Even under lean electrolyte and higher loading $\left(10 \mu \mathrm{L} \mathrm{mA} \mathrm{h}^{-1}\right.$ and $\left.13.8 \mathrm{mg} \mathrm{cm}^{-2}\right)$, LFP cathode still shows superior cycling stability. These excellent electrochemical performances of LS/LN-Li anode demonstrate that the construction of a composite substrate on Li metal is an extremely significant strategy for achieving accurate regulation of Li nucleation, diffusion, and horizontal growth to solve the $\mathrm{Li}$ dendrite growth problem and suppress the side reaction between Li metal anode and liquid electrolyte.

\section{Received 5 December 2020; accepted 23 February 2021;} published online 30 April 2021

1 Wu F, Yuan YX, Cheng XB, et al. Perspectives for restraining harsh lithium dendrite growth: Towards robust lithium metal anodes. Energy Storage Mater, 2018, 15: 148-170

2 Xu W, Wang J, Ding F, et al. Lithium metal anodes for rechargeable batteries. Energy Environ Sci, 2013, 7: 513-537

3 Tarascon JM, Armand M. Issues and challenges facing rechargeable lithium batteries. Nature, 2001, 414: 359-367

4 Bruce PG, Freunberger SA, Hardwick LJ, et al. Li-O $\mathrm{O}_{2}$ and Li-S batteries with high energy storage. Nat Mater, 2012, 11: 19-29

5 Xiao Y, Xu R, Yan C, et al. Waterproof lithium metal anode enabled by cross-linking encapsulation. Sci Bull, 2020, 65: 909-916

6 Wei JY, Zhang XQ, Hou LP, et al. Shielding polysulfide intermediates by an organosulfur-containing solid electrolyte interphase on the lithium anode in lithium-sulfur batteries. Adv Mater, 2020, 32: 2003012

7 Lin D, Liu Y, Cui Y. Reviving the lithium metal anode for highenergy batteries. Nat Nanotech, 2017, 12: 194-206

8 Liu Y, Zhang S, Qin X, et al. In-plane highly dispersed $\mathrm{Cu}_{2} \mathrm{O}$ nanoparticles for seeded lithium deposition. Nano Lett, 2019, 19: 4601-4607

9 Xu R, Yan C, Xiao Y, et al. The reduction of interfacial transfer barrier of $\mathrm{Li}$ ions enabled by inorganics-rich solid-electrolyte interphase. Energy Storage Mater, 2020, 28: 401-406

10 Pathak R, Chen K, Gurung A, et al. Fluorinated hybrid solidelectrolyte-interphase for dendrite-free lithium deposition. Nat Commun, 2020, 11: 93

11 Wu C, Huang $\mathrm{H}, \mathrm{Lu} \mathrm{W}$, et al. Mg doped Li-LiB alloy with in situ formed lithiophilic LiB skeleton for lithium metal batteries. Adv Sci, 2020, 7: 1902643

12 Zhang R, Li NW, Cheng XB, et al. Advanced micro/nanostructures for lithium metal anodes. Adv Sci, 2017, 4: 1600445

13 Shi $\mathrm{P}, \mathrm{Li} \mathrm{T}$, Zhang $\mathrm{R}$, et al. Lithiophilic $\mathrm{LiC}_{6}$ layers on carbon hosts enabling stable Li metal anode in working batteries. Adv Mater, 2019, 31: 1807131

14 Cheng XB, Zhang R, Zhao CZ, et al. Toward safe lithium metal anode in rechargeable batteries: a review. Chem Rev, 2017, 117:
10403-10473

15 Fang C, Li J, Zhang M, et al. Quantifying inactive lithium in lithium metal batteries. Nature, 2019, 572: 511-515

16 Lee D, Sun S, Kwon J, et al. Copper nitride nanowires printed Li with stable cycling for Li metal batteries in carbonate electrolytes. Adv Mater, 2020, 32: 1905573

17 Albertus P, Babinec S, Litzelman S, et al. Status and challenges in enabling the lithium metal electrode for high-energy and low-cost rechargeable batteries. Nat Energy, 2018, 3: 16-21

18 Liu B, Zhang JG, Xu W. Advancing lithium metal batteries. Joule, 2018, 2: 833-845

19 Yan C, Cheng XB, Yao YX, et al. An armored mixed conductor interphase on a dendrite-free lithium-metal anode. Adv Mater, 2018, 30: 1804461

20 Zhu J, Chen J, Luo Y, et al. Lithiophilic metallic nitrides modified nickel foam by plasma for stable lithium metal anode. Energy Storage Mater, 2019, 23: 539-546

21 Yun Q, He YB, Lv W, et al. Chemical dealloying derived 3D porous current collector for Li metal anodes. Adv Mater, 2016, 28: 69326939

22 Zhao H, Lei D, He YB, et al. Compact 3D copper with uniform porous structure derived by electrochemical dealloying as dendrite-free lithium metal anode current collector. Adv Energy Mater, 2018, 8: 1800266

23 Lin D, Liu Y, Liang Z, et al. Layered reduced graphene oxide with nanoscale interlayer gaps as a stable host for lithium metal anodes. Nat Nanotech, 2016, 11: 626-632

24 Luo L, Li J, Yaghoobnejad Asl H, et al. A 3D lithiophilic $\mathrm{Mo}_{2} \mathrm{~N}$ modified carbon nanofiber architecture for dendrite-free lithiummetal anodes in a full cell. Adv Mater, 2019, 31: 1904537

25 Wu H, Zhang Y, Deng Y, et al. A lightweight carbon nanofiberbased 3D structured matrix with high nitrogen-doping level for lithium metal anodes. Sci China Mater, 2019, 62: 87-94

26 Kong SK, Kim BK, Yoon WY. Electrochemical behavior of Lipowder anode in high Li capacity used. J Electrochem Soc, 2012, 159: A1551-A1553

27 Zhao Q, Hao X, Su S, et al. Expanded-graphite embedded in lithium metal as dendrite-free anode of lithium metal batteries. J Mater Chem A, 2019, 7: 15871-15879

28 Ye $\mathrm{H}$, Zheng ZJ, Yao HR, et al. Guiding uniform Li plating/ stripping through lithium-aluminum alloying medium for long-life Li metal batteries. Angew Chem Int Ed, 2019, 58: 1094-1099

29 Zhang D, Dai A, Wu M, et al. Lithiophilic 3D porous CuZn current collector for stable lithium metal batteries. ACS Energy Lett, 2020, 5: 180-186

30 Li W, Yao H, Yan K, et al. The synergetic effect of lithium polysulfide and lithium nitrate to prevent lithium dendrite growth. Nat Commun, 2015, 6: 7436

31 Liu Y, Qin X, Zhou D, et al. A biscuit-like separator enabling high performance lithium batteries by continuous and protected releasing of $\mathrm{NO}_{3}{ }^{-}$in carbonate electrolyte. Energy Storage Mater, 2020, 24: 229-236

32 Ota $\mathrm{H}$, Sakata $\mathrm{Y}$, Otake $\mathrm{Y}$, et al. Structural and functional analysis of surface film on $\mathrm{Li}$ anode in vinylene carbonate-containing electrolyte. J Electrochem Soc, 2004, 151: A1778

33 Zhang XQ, Cheng XB, Chen X, et al. Fluoroethylene carbonate additives to render uniform Li deposits in lithium metal batteries. Adv Funct Mater, 2017, 27: 1605989

34 Ding F, Xu W, Graff GL, et al. Dendrite-free lithium deposition via self-healing electrostatic shield mechanism. J Am Chem Soc, 2013, 
135: 4450-4456

35 Wang L, Wang Q, Jia W, et al. Li metal coated with amorphous $\mathrm{Li}_{3} \mathrm{PO}_{4}$ via magnetron sputtering for stable and long-cycle life lithium metal batteries. J Power Sources, 2017, 342: 175-182

36 Liu Y, Lin D, Yuen PY, et al. An artificial solid electrolyte interphase with high Li-ion conductivity, mechanical strength, and flexibility for stable lithium metal anodes. Adv Mater, 2017, 29: 1605531

37 Tang W, Yin X, Kang S, et al. Lithium silicide surface enrichment: a solution to lithium metal battery. Adv Mater, 2018, 30: 1801745

38 Li G, Liu Z, Wang D, et al. Electrokinetic phenomena enhanced lithium-ion transport in leaky film for stable lithium metal anodes. Adv Energy Mater, 2019, 9: 1900704

39 Yan C, Yuan H, Park HS, et al. Perspective on the critical role of interface for advanced batteries. J Energy Chem, 2020, 47: 217-220

40 Yan C, Xu R, Xiao Y, et al. Toward critical electrode/electrolyte interfaces in rechargeable batteries. Adv Funct Mater, 2020, 30: 1909887

41 Xie J, Ye J, Pan F, et al. Incorporating flexibility into stiffness: Selfgrown carbon nanotubes in melamine sponges enable a lithiummetal-anode capacity of $15 \mathrm{~mA} \mathrm{~h} \mathrm{~cm}{ }^{-2}$ cyclable at $15 \mathrm{~mA} \mathrm{~cm}^{-2}$. Adv Mater, 2018, 31: 1805654

42 Liu S, Ji X, Yue J, et al. High interfacial-energy interphase promoting safe lithium metal batteries. J Am Chem Soc, 2020, 142: 2438-2447

43 Cui C, Yang C, Eidson N, et al. A highly reversible, dendrite-free lithium metal anode enabled by a lithium-fluoride-enriched interphase. Adv Mater, 2020, 32: 1906427

44 Li N, Zhang K, Xie K, et al. Reduced-graphene-oxide-guided directional growth of planar lithium layers. Adv Mater, 2020, 32: 1907079

45 Zhang D, Wang S, Li B, et al. Horizontal growth of lithium on parallelly aligned MXene layers towards dendrite-free metallic lithium anodes. Adv Mater, 2019, 31: 1901820

46 Kohn W, Sham LJ. Self-consistent equations including exchange and correlation effects. Phys Rev, 1965, 140: A1133-A1138

47 Monkhorst HJ, Pack JD. Special points for Brillouin-zone integrations. Phys Rev B, 1976, 13: 5188-5192

$48 \mathrm{Xu} \mathrm{Z}$, Zhu H. Two-dimensional manganese nitride monolayer with room temperature rigid ferromagnetism under strain. J Phys Chem C, 2018, 122: 14918-14927

49 Henkelman G, Uberuaga BP, Jónsson H. A climbing image nudged elastic band method for finding saddle points and minimum energy paths. J Chem Phys, 2000, 113: 9901-9904

50 Wan M, Kang S, Wang L, et al. Mechanical rolling formation of interpenetrated lithium metal/lithium tin alloy foil for ultrahighrate battery anode. Nat Commun, 2020, 11: 829

51 Naille $\mathrm{S}$, Dedryvère R, Martinez $\mathrm{H}$, et al. XPS study of electrode/ electrolyte interfaces of $\eta-\mathrm{Cu}_{6} \mathrm{Sn}_{5}$ electrodes in Li-ion batteries. J Power Sources, 2007, 174: 1086-1090

52 Li JT, Swiatowska J, Seyeux A, et al. XPS and ToF-SIMS study of Sn-Co alloy thin films as anode for lithium ion battery. J Power Sources, 2010, 195: 8251-8257

$53 \mathrm{Fu} \mathrm{R}, \mathrm{Wu} \mathrm{Y}$, Fan $\mathrm{C}$, et al. Reactivating $\mathrm{Li}_{2} \mathrm{O}$ with nano-Sn to achieve ultrahigh initial Coulombic efficiency $\mathrm{SiO}$ anodes for $\mathrm{Li}$ ion batteries. ChemSusChem, 2019, 12: 3377-3382

54 Park K, Yu BC, Goodenough JB. $\mathrm{Li}_{3} \mathrm{~N}$ as a cathode additive for high-energy-density lithium-ion batteries. Adv Energy Mater, 2016, 6: 1502534

55 Zhang YJ, Wang W, Tang H, et al. An ex-situ nitridation route to synthesize $\mathrm{Li}_{3} \mathrm{~N}$-modified $\mathrm{Li}$ anodes for lithium secondary batteries. J Power Sources, 2015, 277: 304-311

56 Shi K, Wan Z, Yang L, et al. In situ construction of an ultra-stable conductive composite interface for high-voltage all-solid-state lithium metal batteries. Angew Chem Int Ed, 2020, 59: 11784-11788

57 Inoue $\mathrm{Y}$, Nomiya $\mathrm{M}$, Takai O. Physical properties of reactive sputtered tin-nitride thin films. Vacuum, 1998, 51: 673-676

58 Yoshida T, Sawada S. X-ray photoelectron spectroscopy of EDTA. Bull Chem Soc Jpn, 1974, 47: 50-53

59 Robinson KS, Sherwood PMA. X-ray photoelectron spectroscopic studies of the surface of sputter ion plated films. Surf Interface Anal, 1984, 6: 261-266

60 Laidani N, Vanzetti L, Anderle M, et al. Chemical structure of films grown by AlN laser ablation: an X-ray photoelectron spectroscopy study. Surf Coatings Tech, 1999, 122: 242-246

61 Liu S, Xia X, Deng S, et al. In situ solid electrolyte interphase from spray quenching on molten Li: a new way to construct high-performance lithium-metal anodes. Adv Mater, 2019, 31: 1806470

$62 \mathrm{Xu} \mathrm{T}, \mathrm{Gao} \mathrm{P}, \mathrm{Li} \mathrm{P}$, et al. Fast-charging and ultrahigh-capacity lithium metal anode enabled by surface alloying. Adv Energy Mater, 2020, 10: 1902343

63 Wang T-, Liu X, Zhao X, et al. Regulating uniform Li plating/ stripping via dual-conductive metal-organic frameworks for highrate lithium metal batteries. Adv Funct Mater, 2020, 30: 2000786

64 Zhou H, Yu S, Liu H, et al. Protective coatings for lithium metal anodes: recent progress and future perspectives. J Power Sources, 2020, 450: 227632

65 Liu F, Xiao Q, Wu HB, et al. Fabrication of hybrid silicate coatings by a simple vapor deposition method for lithium metal anodes. Adv Energy Mater, 2018, 8: 1701744

66 Zhang C, Lan Q, Liu Y, et al. A dual-layered artificial solid electrolyte interphase formed by controlled electrochemical reduction of LiTFSI/DME- $\mathrm{LiNO}_{3}$ for dendrite-free lithium metal anode. Electrochim Acta, 2019, 306: 407-419

67 Xiong S, Xie K, Diao Y, et al. On the role of polysulfides for a stable solid electrolyte interphase on the lithium anode cycled in lithiumsulfur batteries. J Power Sources, 2013, 236: 181-187

68 Zhang A, Fang X, Shen C, et al. A carbon nanofiber network for stable lithium metal anodes with high Coulombic efficiency and long cycle life. Nano Res, 2016, 9: 3428-3436

$69 \mathrm{Ma} \mathrm{J}, \mathrm{Yu} \mathrm{L}, \mathrm{Fu} \mathrm{ZW}$. Electrochemical and theoretical investigation on the reaction of transition metals with $\mathrm{Li}_{3} \mathrm{~N}$. Electrochim Acta, 2006, 51: 4802-4814

70 Zhang Y, Wang C, Pastel G, et al. 3D wettable framework for dendrite-free alkali metal anodes. Adv Energy Mater, 2018, 8: 1800635

71 Luo Z, Liu C, Tian Y, et al. Dendrite-free lithium metal anode with lithiophilic interphase from hierarchical frameworks by tuned nucleation. Energy Storage Mater, 2020, 27: 124-132

72 Jiang Y, Jiang J, Wang Z, et al. $\mathrm{Li}_{4.4} \mathrm{Sn}$ encapsulated in hollow graphene spheres for stable Li metal anodes without dendrite formation for long cycle-life of lithium batteries. Nano Energy, 2020, 70: 104504

73 Cheng XB, Zhao MQ, Chen C, et al. Nanodiamonds suppress the growth of lithium dendrites. Nat Commun, 2017, 8: 336

74 Zhang T, Lu H, Yang J, et al. Stable lithium metal anode enabled by a lithiophilic and electron/ion conductive framework. ACS Nano, 2020, 14: 5618-5627

75 Li Y, Sun Y, Pei A, et al. Robust pinhole-free $\mathrm{Li}_{3} \mathrm{~N}$ solid electrolyte grown from molten lithium. ACS Cent Sci, 2018, 4: 97-104 
76 Schwarz K. Quantum-mechanical calculations based on density functional theory. Phase Transs, 1994, 52: 109-122

77 Ye $\mathrm{S}$, Wang L, Liu F, et al. $\mathrm{g}-\mathrm{C}_{3} \mathrm{~N}_{4}$ derivative artificial organic/ inorganic composite solid electrolyte interphase layer for stable lithium metal anode. Adv Energy Mater, 2020, 10: 2002647

78 Lin K, Qin X, Liu M, et al. Ultrafine titanium nitride sheath decorated carbon nanofiber network enabling stable lithium metal anodes. Adv Funct Mater, 2019, 29: 1903229

79 Liu Y, Xiong S, Deng J, et al. Stable Li metal anode by crystallographically oriented plating through in-situ surface doping. Sci China Mater, 2020, 63: 1036-1045

Acknowledgements This work was supported by the Key-Area Research and Development Program of Guangdong Province (2020B090919001), the National Natural Science Foundation of China (U2001220), Local Innovative Research Teams Project of Guangdong Pearl River Talents Program (2017BT01N111), Shenzhen Technical Plan Project (JCYJ20180508152210821, JCYJ20170817161221958, and JCYJ20180508152135822), the All-Solid-State Lithium Battery Electrolyte Engineering Research Center (XMHT202002030), and Shenzhen Graphene Manufacturing Innovation Center (201901161513).

Author contributions $\mathrm{He}$ YB conceived and supervised the project. $\mathrm{Yu}$ J, Shi K, and $\mathrm{He} \mathrm{YB}$ designed the experiments. Yu J carried out the preparation of electrode materials, material characterization, electrochemical measurements, and data analysis. Zhang $\mathrm{S}$ conducted the calculations. Zhang D, Chen L, Li S and Ma J assisted the preparation of electrode materials. Xia H performed the TEM analysis. Yu J, Shi K, Zhang S, and He YB co-wrote the paper. He YB revised the manuscript. All authors contributed to the general discussion.

Conflict of interest The authors declare that they have no conflict of interest.

Supplementary information Experimental details and supporting data are available in the online version of the paper.

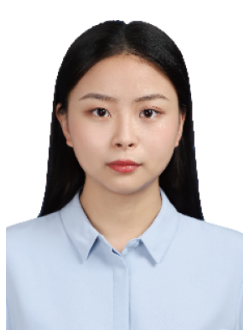

Jing $\mathbf{Y u}$ is currently a Master candidate at Tsinghua Shenzhen International Graduate School, Tsinghua University. She obtained her BS degree (2018) in functional materials from Hebei University of Technology in China. Her research mainly focuses on the design and preparation of high-performance lithium metal anodes for high energy-density lithium batteries.

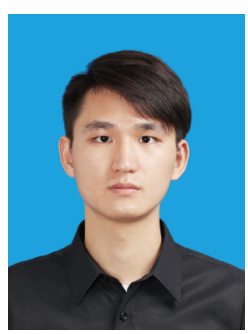

Kai Shi is currently a $\mathrm{PhD}$ candidate at Helmholtz Institute Ulm (HIU), Karlsruhe Institute of Technology (KIT). He received his BS degree at Nanjing University of Aeronautics and Astronautics, and Master degree at Tsinghua University. His current research mainly focuses on the organic batteries and solid electrolyte/electrode interfaces.

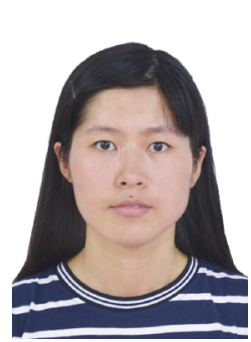

Siwei Zhang obtained her $\mathrm{PhD}$ degree from Tsinghua University in 2020 . She is now working as a postdoctoral research fellow at Hong Kong University of Science and Technology. Her main research interests focus on the theoretical simulation of the working mechanism of energy storage batteries, especially the first principle and molecular dynamic simulation on Li-metal anodes and lithium-sulfur batteries.

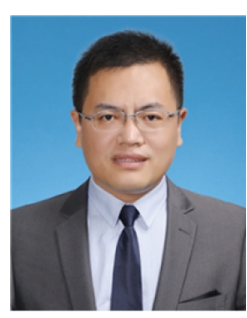

Yan-Bing $\mathrm{He}$ is currently a tenured associate professor of Tsinghua Shenzhen International Graduate School, Tsinghua University. He received his $\mathrm{PhD}$ degree from the Department of Applied Chemistry, Tianjin University in 2010. $\mathrm{He}$ worked as a post-doctoral fellow at the Graduate School at Shenzhen, Tsinghua University from 2010 to 2012 and a visiting scholar at Hong Kong University of Science and Technology from 2012 to 2013. His research interests mainly focus on lithium-ion power batteries and materials, solid-state electrolytes and lithium metal anodes.

\section{一种控制锂金属负极水平沉积的锂形核-扩散-生 长机制}

俞静 $^{1,2 \dagger}$, 石凯 ${ }^{1,2 \dagger}$, 张思伟 ${ }^{3 \dagger}$, 张丹丰 ${ }^{1,2}$, 陈立坤 ${ }^{1,2}$, 李松 ${ }^{1,2}$, 马家宾 ${ }^{1,2}$, 夏和監 ${ }^{1,2}$, 贺艳兵 ${ }^{1^{*}}$

摘要 严重的锂枝晶生长导致锂金属电池的循环稳定性差、安全 隐患大，完全阻碍了其实际应用. 本文提出了一种基于 $\mathrm{Li}-\mathrm{Sn} / \mathrm{Li}_{3} \mathrm{~N}$ 复合界面层的锂形核-扩散-生长机制, 利用两组分的协同作用引导 锂的水平沉积, 从而抑制锂枝晶的垂直生长以及锂金属与电解液 之间的副反应. 在锂沉积过程中, 亲锂的 $\mathrm{Li}-\mathrm{Sn}$ 合金优先捕获 $\mathrm{Li}^{+}$在 合金位点上形核，同时具有低扩散能垒和高锂离子电导率的 $\mathrm{Li}_{3} \mathrm{~N}$ 有效地将锂离子传输至形核位点, 最终促进锂的横向生长. 因此, 即使在 $5 \mathrm{~mA} \mathrm{~cm}^{-2}$ 的高电流密度和 $5 \mathrm{~mA} \mathrm{~h} \mathrm{~cm}^{-2}$ 的大沉积容量下, 组装的对称电池也可以稳定循环 $1600 \mathrm{~h}$. 与负载高达 $8.2 \mathrm{mg} \mathrm{cm}^{-2}$ 的 $\mathrm{LiFePO}_{4}$ 正极组装的电池, 在循环 1000 圈以后, 容量保持率为 $93.4 \%$, 远高于未修饰锂片 (64.8\%). 此外, $\mathrm{Li}-\mathrm{Sn} / \mathrm{Li}_{3} \mathrm{~N}$ 修饰的锂负极与 $\mathrm{LiNi}_{0.8} \mathrm{Co}_{0.1} \mathrm{Mn}_{0.1} \mathrm{O}_{2}$ 正极组装的电池循环稳定性也明显优于未修饰 锂片组装的电池. 锂成核-扩散-生长机制为解决垂直生长的锂枝晶 难题、实现高稳定锂金属电池开辟了一条有前景的途径. 